\title{
Surveying: A Brief Introduction
}

\author{
J. Selvi .M.E. \\ (Ph.D),Professor/Civil Engineering, V.M.K.V.ENGINEERING COLLEGE, Periyaseeragapadi, Salem - \\ 636308, Tamil Nadu, India.
}

\begin{abstract}
Surveying is an interesting subject in Civil Engineering. In this article the author dealt with a brief introduction to this subject with the classification of the instruments and also various classification of surveying. It is very interesting to know in what way the surveying instruments can be used in Civil field and about various application of these instruments. It is sure this article makes sure that it will originate the interest of studying this subject more and more. It is not only an interesting one but also useful one too.
\end{abstract}

Keywords: Definition; Classifications; Instruments involved; Chain; Compass; Level; Theodolite; Process of doing surveying; Advantages and Disadvantages; good photos of the instruments.

\section{Introduction:}

What is Surveying? Surveying is nothing but an art of making measurements on the earth, above the earth and beneath the earth. Surveying is basically divided into two Categories. One is Geodetic Surveying and the Other is Plane Surveying. This classification is made up on the consideration of curvature of the earth. We know the shape of earth is Hemisphere. How will you prove it? If we stand on the floor we can see anything along the same line of sight which means we are standing on a flat earth. In earlier days people also thought like this and they didn't want to travel far away as they feared when they reach the end or edge they would fell down. But our explorers going on doing adventures to go farer and farer and at last one great person named Galileo start from and proceed in the same direction through sea and after a long time he reached the same starting place. Yes! He proved that earth is not flat and it is round one.

Another proof for the shape of the earth is if we stand on the sea shore and watch the ship approaching us, we can first see the top most portion of the ship and slowly the middle portion appears to our eyes and then lastly we see the bottom portion that is the whole ship. This is possible only when the earth is spherical not a flat one.

Above said are the only earlier proofs and here mentioned only to recall it. Now we are living in a very modern world. So that man can move to space and take photograph of earth which shows the shape of the earth.

What is the connection between the this shape and the surveying? Yes, here it comes. According to our human eye, line joining any two points on earth is a straight line whereas in reality the line joining any two points is a curve.

If the surveying is done neglecting the effect of curvature of earth, then it is called plane surveying. If the effect of curvature of earth is taken into account then it is called Geodetic surveying.

Apart from these two basic classifications there are so many other classifications of surveying. Some of them are listed below.

(i) Depending upon the field
(a) Land Surveying
(b) Aeronautical Surveying
(c) Marine Surveying
(d) Mine Surveying

(ii) Depending upon the purpose

(a) Road Surveying

(b) Railway Surveying

(c) Bridge Surveying

(d) Dam Surveying

(e) Quantitative Surveying

(f) Military Surveying

(g) Astronomical Surveying

(h) Geological Surveying

(i) Astronomical Surveying

(j) Archaeological Surveying 


\section{(iii) Depending upon the Accuracy}

(a) Preliminary Surveying

(b) Detailed Surveying

(iv) Depending upon the Instruments

(a) Chain Surveying

(b) Compass Surveying

(c) Plane Table Surveying

(d) Leveling

(e) Theodolite Surveying

(f) Tachometric Surveying

(g) Photographic Surveying

There are so many other types of classifications also. We should know briefly about each every thing.

(i) Land Surveying: This includes

(a) Topographical Surveying: This consists of horizontal and vertical location of certain points by linear and angular measurements and is made to determine the natural features of a country such as rivers, streams, lakes, woods, hills etc., and such artificial features as roads, railways, canals towns and villages.

(b) Cadastral Surveying: They are made incident to the fixing of property lines, the calculation of land area, or the transfer of land property from one owner to the another. They are also made to fix the boundaries of municipalities and of State and Federal jurisdictions.

(C) City Surveying : They are made in connection with the construction of streets, water supply systems, sewers and other works

(ii) Marine Surveying:

It deals with bodies of water for the purpose of navigation, water supply, harbor works or for determining MSL.

(iii) Mine Surveying:

This is used for exploring the mineral wealth.

(iv) Military Surveying:

This is used for determining the points of strategic importance.

(v) Geological Surveying:

This is used for finding different strata in the earth's crust.

(vi) Archaeological Surveying:

This used for unearthing relics of antiquity.

(vii)Chain Surveying:

It is that type of surveying in which only linear measurements are made in the field. This is used for surveys of small extent on open ground to secure data for exact description of the boundaries of a piece of land.

\section{Introduction:}

\section{Chain Surveying:}

The other name for chain Surveying is chain triangulation as it consists of number of Triangles. To get good results in plotting, the frame work should consist of as many equilateral triangles as possible.

Survey Lines: There are three types of important chain lines. They are

(i) Base line

(ii) Check line

(iii) Tie line

Base Line: The longest chain line in a chain survey is plot is called Base Line.

Check line: Check lines are otherwise known as proof lines are lines which run in the field to check the accuracy of work. A check line may be laid by joining the apex of the triangle to any point on the opposite side or by joining two points on any two sides of the triangle.

Tie lines: A Tie line is a line which joins subsidiary or Tie stations on the main base line. The main object of running a Tie line is to take the details of nearly objects but it also serves the purpose of a check line.

\section{Instruments used in Chain Surveying:}

(i)Chain: The different types chains available are

(a) Metric Chain

(b) Gunter's chain or Surveyor's chain 
(C) Engineer's chain

(d)Revenue Chain

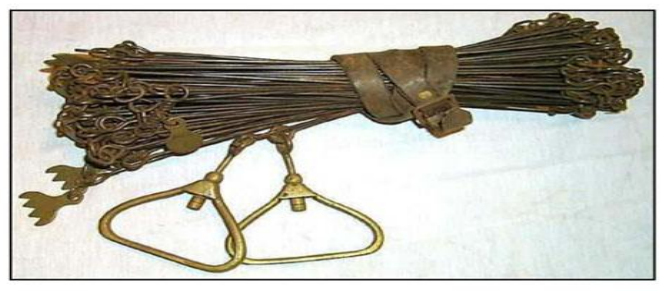

Fig. 1

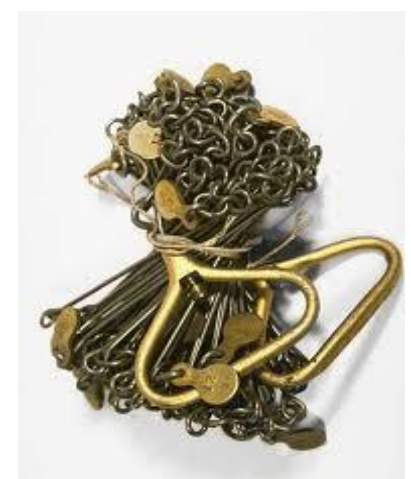

Ref.: Images for photos of surveying instruments chain.

Fig. 2

(ii) Arrows

(iii) Pegs

(iv) Ranging rods

(v) Offset rods

(vi) Plasterer laths and whites

(vii) Plumb bobs

(viii) Field book

\section{Process of doing Chain Surveying:}

For doing the Chain Surveying mainly two persons namely Surveyor and Follower are needed. As we know Chain Survey is nothing but making linear measurements in a field, we have to enter the readings in the field book namely offsets and chain lengths to the important stations and with the help of which we can plot the complete plot in the office.

The Surveyor unfold the chain and throw it forcefully holding the two handles strongly in his hand. Then one handle will be with the Surveyor and the follower take the other handle and drag it on the base line. The Surveyor will give the instructions (Alignment) to make it straight. Then offsets are taken by using the tape. Each offsets should have its value and chain length.

Office Work: This includes the plotting of the required framework and prepare the plan.

Compass Surveying: The main process of Compass Surveying lies in understanding some important terms.

(i) Meridian

(ii) Bearing

(iii) Local Attraction

(iv) Magnetic Declination

(v) Dip

Meridian: There are three types of meridians available. 
(i) True Meridian

(ii) Magnetic Meridian

(iii) Arbitary Meridian

True Meridian: The imaginary line joining the North and South pole of the Earth is called True Meridian.

Magnetic Meridian: The direction shown by the freely oscillating needle is called Magnetic Meridian.

Arbitary Meridian: Any line we draw and mark North and South is called Arbitary Meridian.

(ii) Bearing: Bearing is nothing but the angle measured from the meridian and the corresponding line. Various types of bearing are
(a) True Bearing
(b) Magnetic Bearing
(c) Arbitary Bearing
(d) Whole Circle Bearing
(e) Reduced Bearing
(f) Fore Bearing
(g) Back Bearing

\section{True Bearing:}

It is the bearing or angle measured from the True Meridian.

\section{Magnetic Bearing:}

It is the bearing or angle measured from the Magnetic Meridian.

\section{Arbitary Bearing:}

It is the bearing or angle measured from the Arbitary Meridian.

\section{Whole Circle Bearing:}

This is denoted by W.C.B. It is angle measured from North in clockwise direction from the meridian. The minimum and maximum values are $0^{\circ}$ and $360^{\circ}$.

\section{Reduced Bearing:}

This is denoted by R.B. It is the angle measured either from North or from South whichever is nearer to the line under consideration either in clockwise or anticlockwise direction from the meridian. The minimum and maximum values are $0^{\circ}$ and $90^{\circ}$. It should be mentioned with the Quadrant in which they present.

Fore Bearing: It is the bearing measured from the far end of a line.

Back Bearing: It is the bearing measured from the rear end of a line.

The difference between the Fore Bearing and the Back Bearing is always $180^{\circ}$.

\section{Instruments involved:}

The following instruments are involved in doing the Compass Surveying.

(i) Compass

(ii) Ranging Rods

(i)Compass : It is of two types

(a) Prismatic Compass

(b) Surveyor's Compass

\section{Prismatic Compass}

This Prismatic Compass is a fully functional Prismatic Surveying Compass and yields reasonably accurate results. It comes with an aluminum tripod and canvas cases. The design of the Prismatic Compass allows the user to simultaneously view the object being sighted and its magnetic heading with approximately $1 / 2$ degree resolution. The compass case and lid is solid brass with a black powder coating. The rear sight is machined aluminum. The prism can be flipped up for use as a front sight, and at the same time view the compass heading. There are two colored filters that can be placed in the optical path of the measurement to reduce glare. 
There is a small cover that can be swung into place to protect the prism. The degree markings on the compass rose are stamped mirror image so the heading reads properly when viewed through the prism. When taking a heading measurement, the magnetic heading appears clearly under the object being sighted. Two adjustment screws allow the height of the prism to be precisely set for proper focus. Pressing a small plunger button near the rear sight locks the compass card for easier reading. The compass has a needle lift mechanism to protect the agate compass jeweled bearing when being transported. The rear sight has a replaceable thread and a hinged mirror that can also be raised or lowered. The compass can be threaded onto the lightweight surveyor's tripod with a ball and socket head using standard 3/4 inch x 24 threads. The compass measures $43 / 8$ inches $(11.1 \mathrm{~cm})$ in diameter, $11 / 2$ inches $(3.8 \mathrm{~cm})$ thick, and weighs one pound, 3 ounces (539 grams). When mounted on its tripod, the height of the compass is adjustable from a minimum height of $121 / 2$ inches $(31.7 \mathrm{~cm})$ tall is a maximum height of 21 inches $(53.3 \mathrm{~cm})$ tall. This compass is accurate with a resolution of about $1 / 2$ a degree. Both the compass and tripod come with canvas cases.

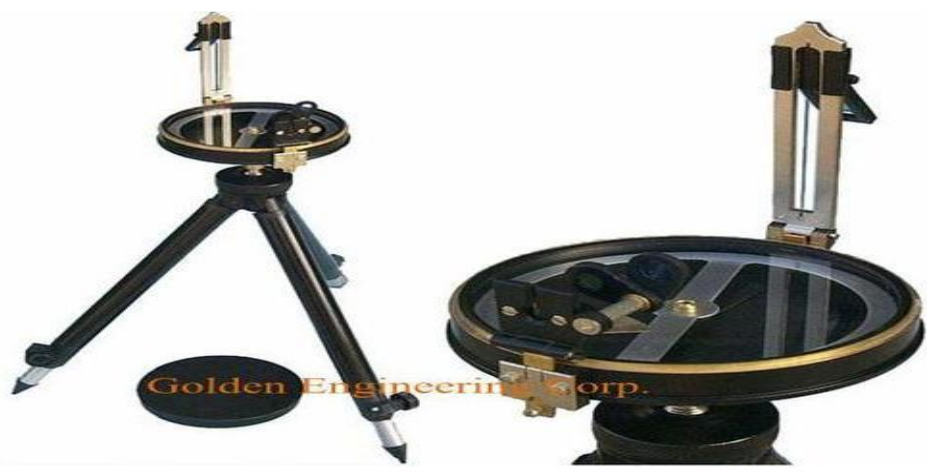

Fig. : 3

Ref.: www.indiamart.com/goldenenggcorp/surveying-instruments.html

The main difference between them are (i) In prismatic Compass a prism is used. The readings are marked in Whole Circle Bearing. They are used in the field.

(ii)In Surveyor's Compass only magnet is used. The readings are marked in Reduced Bearing System, they are used in Ships Aero planes to show the direction.

\section{Local Attraction:}

It is a term used to denote any influence of iron objects like magnetite in the ground, wire carrying electric current, steel structures, rail road rails, underground iron pipes, bunch of keys, metal buttons, axes etc., and preventing the magnetic needle from pointing to the North in a given locality.

This should be checked and corrected.

Dip:

The inclination of the magnetic needle in the vertical direction is called Dip. It is $0^{\circ}$ at Equator and $90^{\circ}$ at the Poles.

\section{Magnetic Declination:}

It is the angle between the True Meridian and Magnetic Meridian.

With the given value of Magnetic Bearing we can find the True Bearing and vise versa.

Plane Table Surveying: Here this topic can be explained under four headings

(i) Accessories used

(ii) Methods of doing Plane Table Surveying

(iii) Advantages

(Iv) Disadvantages

Instruments used: The following Accessaries are used in Plane Table Surveying.

(i) The Plane Table with leveling head having arrangements for (a) leveling (b) rotation about vertical axis (c) clamping in any required position

(ii) Alidade for sighting 


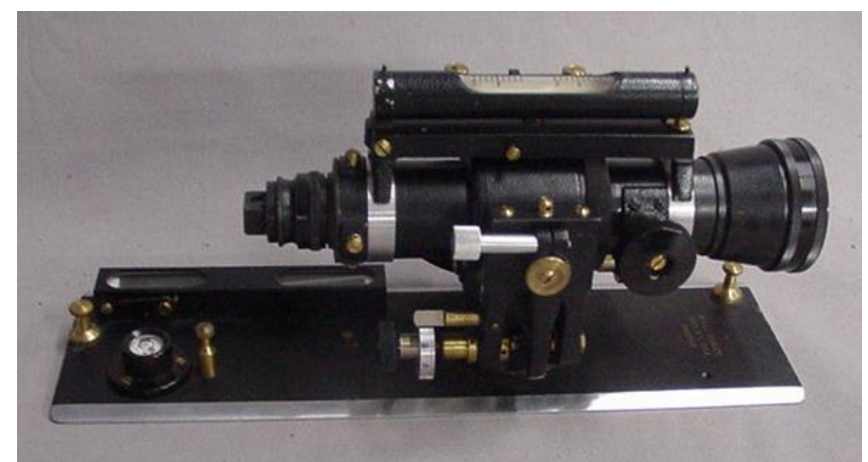

Ref.: 2439b.jpg (JPEG Image 590 x316 pixels), www.antiquesurveying.com/alidades.htm

(iii) Plumbing fork and Plumbing bob

Fig. : 4

(iv) Sprit Level

(v) Compass

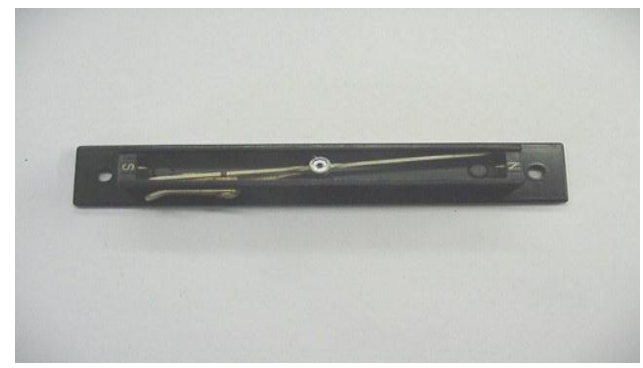

TROUGH COMPASS

Fig.: 5

Trough compass.jpg (JPEG image 640 x 480 pixels), www.antiquesurveying.com/alidades.htm

(vi) Drawing paper with a rainproof cover

\section{Methods of doing Plane Table Surveying:}

There are four types of doing this Surveying.
a. Radiation
b. Intersection
c. Traversing
d. Resection

The first three methods are used to draw the plan on the paper by seeing the object on the ground. The fourth method is used to locate the station occupied by the instrument with the help of two or three known stations. If two stations are involved then it is called Two point Problem. If three stations are involved then it is called Three Point Problem.

\section{Advantages:}

1. Plan is drawn by the out-door Surveyor himself while the country is before his eyes, and therefore, there no possibility of omitting the necessary measurement.

2. The Surveyor can compare plotted work with the actual features of the area.

3. Since the area is in view, contour and irregular object may be represented accurately.

4. Direct measurements may be almost entirely dispensed with, as the linear and angular dimensions are both to be obtained by graphical means.

5. Notes of measurements are seldom required and the possibilities of mistakes in booking is eliminated.

6. It is particularly useful in magnetic areas where compass can not be used.

7. It is simple and hence cheaper than Theodolite or any other type of surveying.

8. It is most suitable for small scale maps.

9. No great skill is required to produce a satisfactory map and the work can be entrusted to a subordinate. 


\section{Disadvantages:}

1. Since notes of measurements are npt recoded, it is a great inconvenience if the map is required to reproduce to some different scale.

2. The Plane Table is not intended to very accurate work.

3. It is essentially a tropical instrument.

4. It is most inconvenient to use this instrument.

5. Due to heaviness it is difficult to transport.

6. Since there are so many accessories, there is every likelihood of these being lost.

\section{LEVELLING}

It is one of the important part of Surveying. Since all other types of Surveying deals with the horizontal measurements whereas leveling deals with vertical measurements. First of all some important terms should be understood.

1. Bench mark : B.M. This is defined as a station with a known Reduced level.

2. Mean Sea Level: M.S.L.The average height of tides appear in the sea.

3. Reduced Level: R.L. It is the level of a station reduced from the R.L. of the Bench Mark.

4. Back Sight : B.S. The very first reading taken from an instrument station.

5. Fore Sight: F.S. The very last reading taken from an instrument station.

6. Inter sight: I.S. All the readings taken in between Back Sight and Fore Sight.

7.Change point : C.P. It is the staff station at which both F.S. from the First instrument station and B.S. from the Second instrument station has takenHeight of Collimation: H.C. It is the R.L. of the line of sight.

\section{Methods of Leveling:}

There are two methods available for doing the Leveling Calculation. They are

(i) Height of Collimation Method

(ii) Rise and Fall Method

Height of Collimation Method deals with the deductions of all stations from a common R.L. of line of sight whereas Rise and Fall method deals with the comparison of R.L.s of successive stations. Out of these two methods the popular method is Rise and Fall Method.

\section{Instruments:}

The main instrument involved in this method are

1. Dumpy Level

2.Tilting Level

3. Leveling Staff

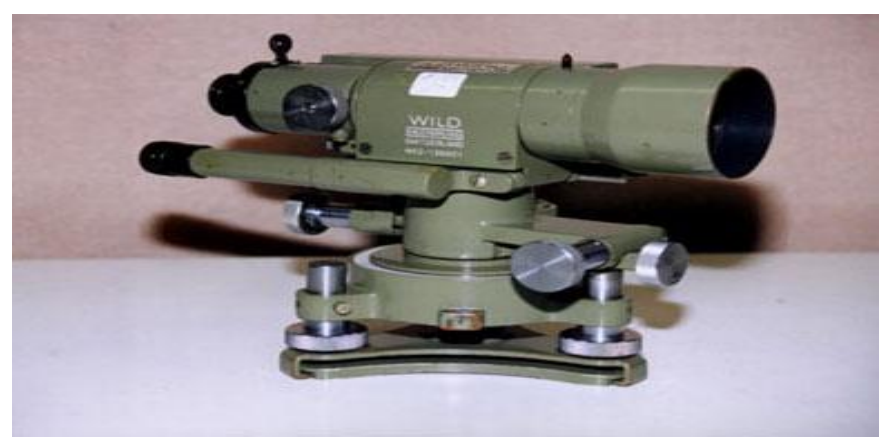

Fig. 6: DUMPY LEVEL

\section{Surveying Instrument Collection}

www.gmat.unsw.edu.au/final_year_thesis/f_pall/html/index.htm

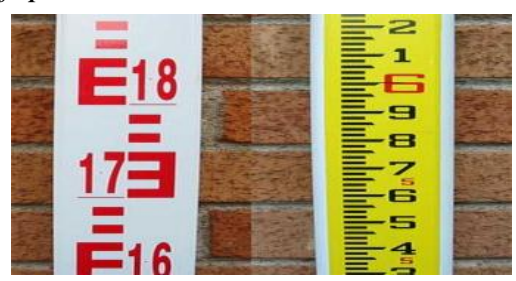

Fig.7: LEVELLING STAFF From Wikipedia, the free encyclopedia

Jump to: navigation, search 
According to the place of Surveying and Locality of Surveying we can select either Dumpy Level or Tilting Level.

The Leveling Staff is made of well seasoned wood or steel. It is usually of folded type. The least count of Leveling Staff is $0.005 \mathrm{~m}$ i.e. $5 \mathrm{~mm}$.

\section{Uses of Leveling:}

1. Leveling is mainly used to calculate R.L.s of various stations.

2. It is very useful in area and volume calculations.

3 . It is used in drawing the contours.

4. It is useful in drawing the Longitudinal sections and Traverse sections.

\section{Theodolite Surveying:}

It is the latest type of Surveying. Here the angular measurements are made between the stations. Here using this Instrument i.e. Theodolite, the horizontal and vertical angles are measured. With the help of which the height of any special structure can be calculated..Radial Contouring easily done with the help of Theodolite.

\section{Vernier Transit Theodolite Watts Pattern}

Watts Theodolite is designed to meet the requirements of Civil Engineer, Surveyor and Mining Engineer for high grade instruments giving a maximum portability. Both circles are totally enclosed making the instruments suitable for work either above or below the ground. The instrument is supplied with standard accessories in teak wood box with aluminum telescopic tripod stand. Our range of products is subject to customization to meet the needs of our clients availed in very reasonable rates.

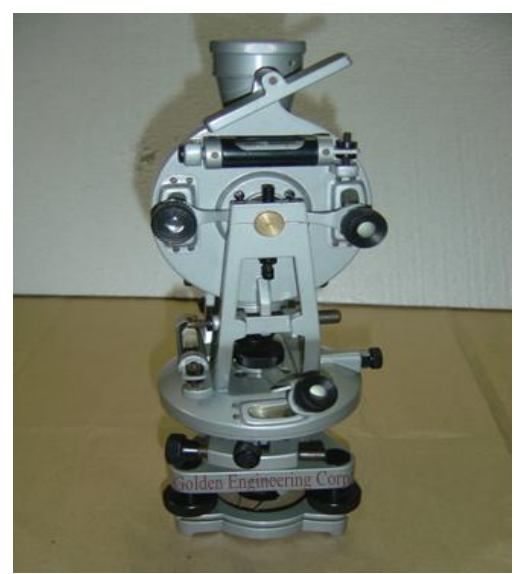

www.indiamart.com/goldenenggcorp/surveying-instruments.html

Fig.: 8

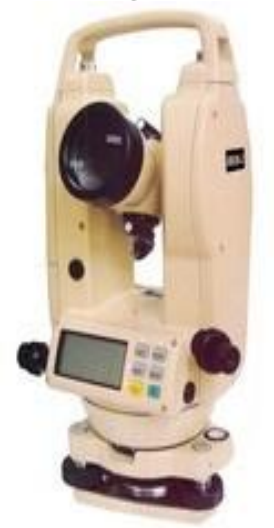

\section{Electronic Theodolite}

\section{Total Station Instrument:}

It is a combination of an Electronic Theodolite and an Electronic Distance Meter (EDM). This combination makes it possible to determine the co ordinates of a reflector by aligning the instrument cross hairs on the reflector and simultaneously measuring the vertical and horizontal angles. and slope distances. 


\section{Conclusion:}

The above article will give actually an introduction to the word Surveying and briefly explains about the purpose and its uses. It will surely creates a keen interest inside the reader to know more about surveying which is the main aim of the article.

\section{References:}

[1] Surveying by B.C .Punmia \& Ashok Jain - Vol.I

[2] Surveying by B.C .Punmia \& Ashok Jain - Vol.II

[3] Surveying - Higher Surveying by B.C .Punmia \& Ashok Jain - Vol.III

[4] Basic Civil Engineering - Dr. B.C punmia \& Ashok Kumar Jain \& Arun Kumar Jain - Page 185

[5] Surveying and Levelling by Punmia

[6] S. K. Duggal, Surveying and Levelling, Vol. I and II, Tata Mc Graw-Hill

[7] B.C Punmia, Surveying, Lakshmi Publ. 1994.

[8] Arora, K.R., "Surveying", Vol. I \& II Standard Book House, Delhi,

[9] T.P. Kanetkar \& S. V, Kulkarni, Surveying and Levelling Part I and II Pune Vidhyarthi Griha Prakashan

[10] Chandra, A.M. "Plane Surveying", New Age International Publishers, Delhi

[11] Kennie, T.J.M. and Petrie, G., "Engineering Surveying Technology", Blackie \& Sons Ltd., London, 1990

[12] N.N.BASAK, Surveying and Leveling, Tata McGraw-Hill

[13] A. M. Chandra, Plane Surveying, New Age International Publishers

[14] S.K.Husain, M.S.Nagaraj, Text book of Surveying, S. Chand and Company

[15] Chandra, A.M. "Higher Surveying", New Age International Publishers, Delhi

[16] Class Notes by Dr. R. Vaidhya Nathan at GCE, Salem. During 1980. 